\title{
Ideology and the text-in-context relation
}

Annabelle Lukin(1)

Correspondence:

annabelle.lukin@mq.edu.au Macquarie University, Sydney, Australia

\begin{abstract}
While aspects of Halliday's theory have been adopted for the study of ideology in discourse - in particular via Critical Discourse Analysis - these applications of his ideas have not attempted to bring the full weight of Halliday's model to the problem of understanding the phenomenon and practical manifestation of ideology. A consideration of Halliday's model reveals, first of all, that Halliday, like Vološinov in linguistics, and Mannheim in sociology, sees ideology as entirely pervasive. The act of analysing ideology is, therefore, ideological, a conundrum known as 'Mannheim's paradox'. This paradox, rather than hindering the study of ideology, invites the researcher to work explicitly with the concepts in one's theoretical model, and to test their usefulness in producing robust and revealing descriptions of the ideologies that shape human experience and behaviour. This paper explores ideology in the context of the 'architecture' of human language, that is, with reference to key concepts in Halliday's theory, including realisation/stratification, instantiation, register and context of situation and of culture. I argue that while ideology is permeable with respect to register - the same ideology can be expressed across a variety of contexts - the concepts of context and register are crucial to showing the affordances of particular registers to the dissemination of specific ideologies. I illustrate this claim by analysing one text with respect to its context of situation (drawing on Hasan's context networks) and its context of culture. I consider how the text, as an instance of a particular register, is an ideal host for ideological meanings that legitimate organised violence in the pursuit of geopolitical power.

Keywords: Ideology, Halliday, Hasan, Register, Context of situation, Context of culture
\end{abstract}

'The brain gives us a grip on our world, and the world a grip on us ... We are in the world and the world is in us.'

(Firth 1957a)

\section{Introduction: Ideology, language and linguistics}

Though famously declared dead in the second half of the twentieth century, ideology remains one of the most important concepts in the social sciences (Malešević 2002). Despite the theoretical difficulties in delineating the concept, and the methodological difficulties in making it visible via analysis of concrete expressions of ideology, the term remains essential, in one form or another, to the many disciplines interested in understanding the process by which 'the outside becomes the inside, and ... the inside reveals itself and shapes the outside' (Bernstein 1987: 563). The concept of ideology goes back

(c) The Author(s). 2017 Open Access This article is distributed under the terms of the Creative Commons Attribution 4.0 International License (http://creativecommons.org/licenses/by/4.0/), which permits unrestricted use, distribution, and reproduction in any medium, provided you give appropriate credit to the original author(s) and the source, provide a link to the Creative Commons license, and indicate if changes were made. 
over 200 years to French philosopher, Destutt de Tracey, but the first semiotic account of ideology dates to 1929, with the publication of Vološinov's Marxism and the Philosophy of Language. In this account, Vološinov (1895-1936) describes the sign as the ideological phenomenon 'par excellence'. He presents a view of ideology as something entirely pervasive, arguing that everything that is ideological has semiotic value and that without signs 'there is no ideology' (Vološinov 1973).

This 'total' view of ideology came into European sociology via the work of Karl Mannheim (1893-1947). Mannheim traces the rise of the realisation that individual consciousness is historically contingent. In this process, the fiction of a 'timeless, unchanging "consciousness as such"'is replaced by 'a conception which varies in accordance with historic periods, nations, and social classes' (Mannheim 1936: 68). Human affairs come to be understood not as 'an isolation of their elements'; rather 'every fact and event in an historical period is ... explicable in terms of meaning and meaning in its turn always refers to another meaning'. Mannheim argued that 'this interdependent system of meanings varies both in all its parts and in its totality from one historical period to another' (Mannheim 1936: 68-69).

This total view of ideology in Mannheim's work produced what the anthropologist Clifford Geetz described as 'Mannheim's paradox'. If ideology is pervasive, then one cannot expose another's ideology without also adopting an ideological viewpoint. Some have suggested that the view of ideology as entirely pervasive - as a total worldview, rather than as the Marxist notion of 'false consciousness' removes from the concept of ideology its power of description. Eagleton, for instance, writes:

... if there are no values and beliefs not bound up with power, then the term ideology threatens to expand to vanishing point. Any word which covers everything loses its cutting edge and dwindles to an empty sound. For a term to have meaning, it must be possible to specify what, in particular circumstances, would count as the other of it. (Eagleton 1991: 7-8).

Fairclough, a leading scholar in the field most associated with the study and analysis of ideology in discourse (Critical Discourse Analysis), also rejects the 'total' view of ideology. Fairclough argues that only 'certain uses of language and other "symbolic forms" are ideological'; that discursive practices 'are ideologically invested in so far as they incorporate significations which contribute to sustaining or restructuring power relations' (Fairclough 1992: 91). CDA, he writes is 'a "moderate" or "contingent" form of social constructivism', based on 'a realist approach which claims that there is a real world, including the social world, which exists irrespective of whether or how well we know and understand it' (Fairclough 2010a: 4,5). For Fairclough, it is possible to 'transcend' ideology, and thus to avoid Mannheim's paradox:

Ideologies arise in class societies characterised by relations of domination, and in so far as human beings are capable of transcending such societies they are capable of transcending ideology. I do not therefore accept the view of 'ideology in general' as a form of social cement which is inseparable from society itself" (Fairclough 2010b: 67). 
While Halliday's linguistics is widely applied in CDA - Wodak argues 'an understanding of the basic claims of Halliday's grammar and his approach to linguistic analysis is essential for a proper understanding of CDA' (Wodak 2001: 8) - Halliday does not share Fairclough's views. For Halliday, as for Vološinov, language is ideologically saturated. Grammar is, in Halliday's view an 'ideological interpretant built into language' (Halliday 2003a: 135). And the power of language, its ideological power, derives from this central characteristic. Further, Halliday accepts the implication of this view for academic scholarship, treating linguistic theories as also ideological. Rather than try to avoid Mannheim's paradox, Halliday explicitly describes his theoretical predecessors as his 'ideological antecedents'. These 'ideological antecedents', he writes:

lie not in the formal grammars and truth-conditional semantics of the latter part of the century, but in a more functionally-oriented linguistics: that of Sapir and Whorf, Malinowski and Firth, Bühler, Mathesius and Trubetzkoy, Hjelmslev, Benveniste and Martinet, among many others (Halliday 2003b: 423).

This theoretical difference between Halliday and Fairclough is, perhaps despite appearances, wide-ranging. It pertains not simply to how extensive ideology is, but implicates directly a theory about the nature of language. For Fairclough, language can be agentive in the construction of reality. But if humans can transcend ideology, this means they can also experience the world directly, in an unmediated fashion. Under these conditions, language simply mirrors reality: it is merely a conduit for already existing, universal meaning (Reddy 1979). Halliday rejects entirely the conduit view of language. Indeed, he suggests that when this view of language is taken - a view 'ever present in the field of linguistics' - the resulting vision of language is 'so impoverished that serious questions about language can hardly even be raised, let alone imaginatively pursued' (Halliday 2003c: 237). For Halliday, language is always agentive in the construction of reality, and by extension, is always ideological. Since linguistic theories are also made of language, they do not escape ideological saturation.

If all language is ideological, and all forms of analysis are ideologically infused, how does one make progress on the linguistic analysis of ideology? Is all parole equally ideological? This apparent conundrum is best approached by examining texts in relation to their register properties, and by extension, in relation to the context of situation they both realise and construe. The context of situation provides us the means to relate the text to the context of culture, where the explanation for the function and origins of any ideology lies.

\section{Text, context and ideology}

How does Halliday's linguistic model provide tools for modelling and analysing ideology? Figure 1 sets out two key relations in Halliday's architecture of language, realisation and instantiation, both of which are deeply relevant to understanding how and why ideology is both pervasive and powerful beyond what we fully understand. Taking realisation first of all - a relation Halliday describes as probably the most complex of all linguistic relations - text both realises and is realised by the context of situation, with context of situation modelled as a tripartite structure of field, tenor and mode. These 


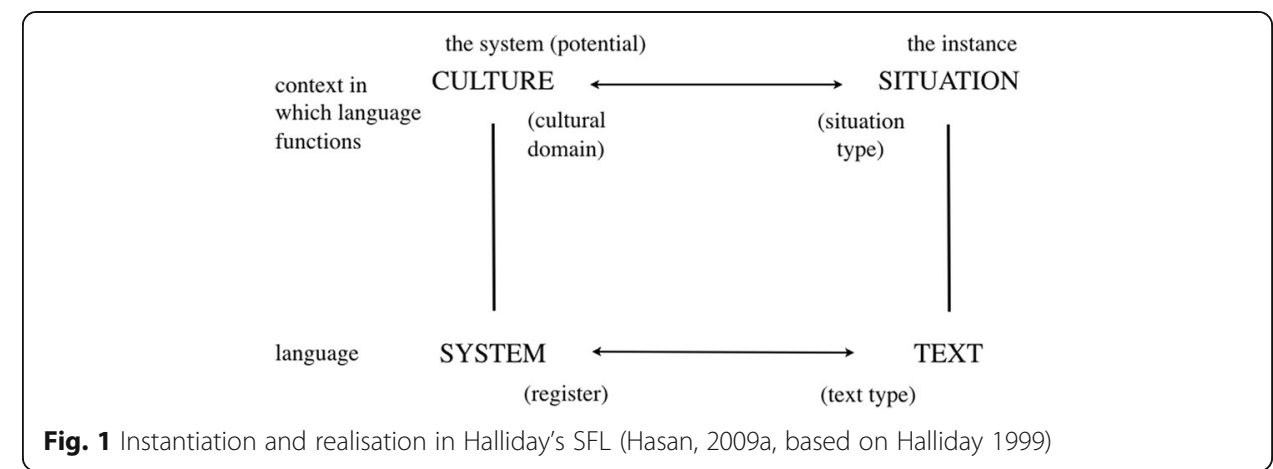

elements of the semiotic structure of context are a reflex of the metafunctional organisation of language: that is, these vectors of context resonate not simply in the instance of a text-in-context configuration, but are part of the organisation of language as a system, having been central to its evolution. Realisation is not singular: the linguistic system combines both conventional and natural modes of realisation, a key feature of language that gives its a rich ideological potential (Lukin forthcoming). The particular assemblage of strata and the realisation relations which obtain between them in Halliday's model give us a picture of a linguistic system deeply rooted in our bodies and in many and our various contexts of living (see Fig. 2). At the same time, language combines the power of arbitrariness at the expression plane, which frees language from the constraints of indexicality and iconicity, with the power of a wholly abstract, metafunctional, lexicogrammar (Halliday 2003b). This combination of relations enabled the collective human consciousness to create 'a semiotic space which is truly elastic, in that it can expand into any number of dimensions' (Halliday 2002: 356).

Halliday complements the picture of the realisation-stratification relation with 'instantiation', the concept by which Halliday relates Malinowski's terms 'context of situation' and 'context of culture'. Malinowski argued that a social context can only be

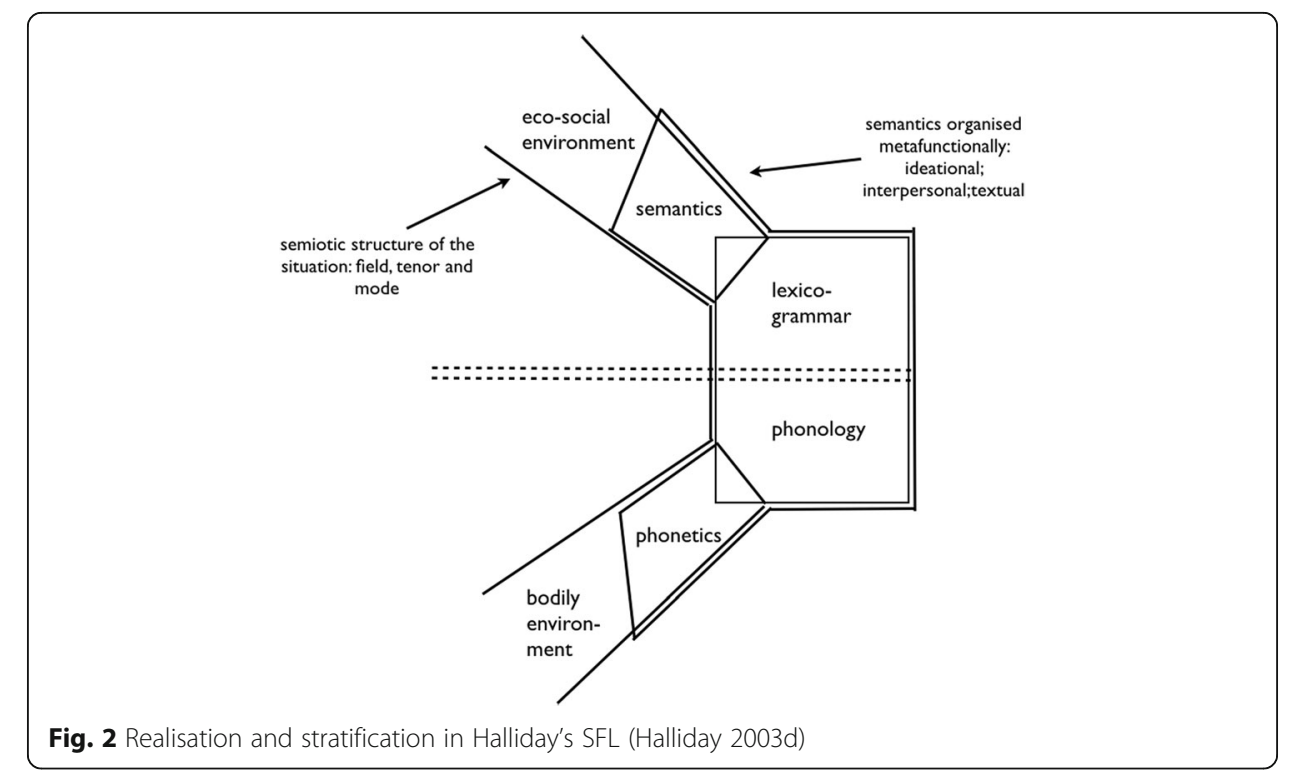


understood if its cultural valeur - the 'context of culture' - is understood. The vector of instantiation, Halliday argues, is the means by which a linguistic system is open and dynamic, rather than circular and self-regulating (Halliday 2002). An ideology forms through repeated manifestations of a pattern of meaning/s. That is, ideologies take shape by being instantiated, through the relationship of instance to system and system to instance. In this process, a culture or community adopts and privileges some kind of semantic configuration rather than another. While registers are the environments for the manifestation of ideology, the wellspring of ideology is the social structure (Hasan 2005a). In other words, the genesis of ideological patterning lies in forms of living, in the context of culture, including in the contests over the distribution of, or access to, communal resources. Thus, context of culture is vital to the explanation of ideologies, whether one is examining linguistically realised ideology or its manifestation via other semiotic modalities.

What is the relationship of ideology to register? It is clear that ideologies cross registerial boundaries, since the same ideological cluster of meanings can be found across many registers. Foucault's concept of 'discursive formation' captures this feature of ideology, defining it as a 'regularity (an order, correlations, positions and functionings, transformations)' between 'objects, types of statement, concepts, or thematic choices' (Foucault 1972: 38). In addition, Hasan has argued that for a dominant ideology to survive it must be supported at 'every level of human experience', otherwise 'the fabric of inevitability is torn and glimpses of an alter-ideology are afforded which have the potential of undermining the credibility of the dominant ideology' (Hasan 2005b). Thus, ideologies cross registerial - and semiotic - boundaries. Looked at from the perspective of speaker, it is also clear that different speakers hold distinct ideological stances. As Mannheim argued, we cannot seem to escape 'the alarming fact' that 'the same world can appear differently to different observers' (Mannheim 1936: 6). Hasan has shown that the texts of the same register display semantic variation, if there is a variation in one key dimension of the tenor, that of social positioning of the speakers (Hasan 2009b). This variation in speaker's social position correlated with a variant sense of what the context was a context for, what was relevant and what was irrelevant, and was realised in a variety of linguistic choices. The same register can be enacted by speakers with variant ideologies, and the resulting textual product will be sensitive to this variation.

Hasan has attempted to model the interconnections of social structure and ideology in text - see Fig. 3 (Hasan 2016a). She offers not a sociolinguistic, but a sociological linguistic interpretation, ${ }^{1}$ with the top half of the diagram dealing essentially in phenomena of a sociological nature, and the lower half being phenomena pertaining to language. The two parts meet around the principles relating to the recognition and participation in contexts of situation - a point of contact which is simultaneously psychological (concerned with internal/internalised phenomena), sociological (mapping the social relations which correlate with orientations to context) and linguistic (postulating the existence of semantic variation, that is, configurations of meaning construed by options in the linguistic system and sensitive to contextual relations). These origins of the principles for interaction, viewed sociologically, are traced to control over communal resources, in interaction with relations of class, race, ethnicity and gender. This complex of factors underlies the processes described by Bernstein to explain how power 


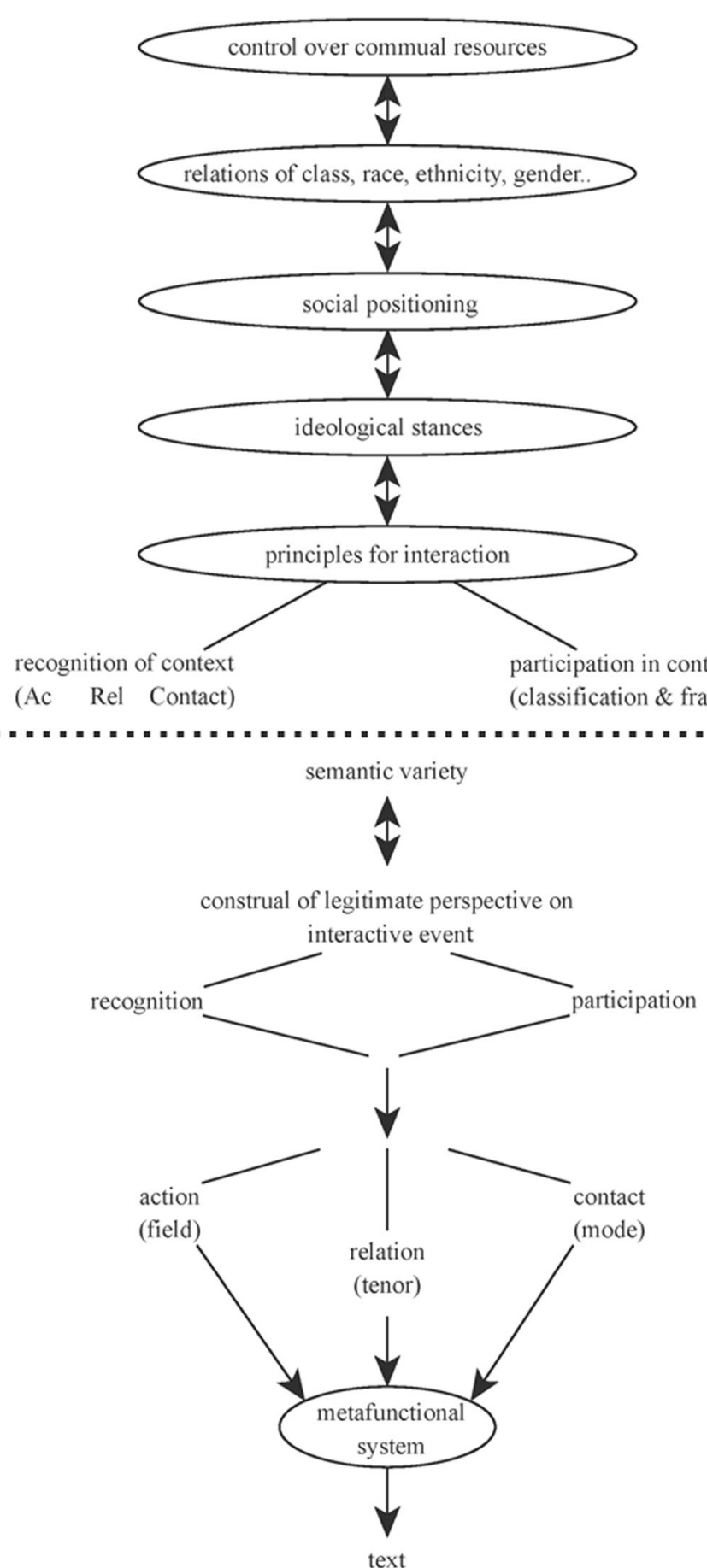

Fig. 3 From social structure to text-in-context (Hasan 2016a)

and control generate, distribute, reproduce and legitimate 'dominant and dominated principles regulating the relationships within and between social groups and so forms of consciousness' (Bernstein 1990: 13). Bernstein attributes the key set of relations here as class relations; Hasan adds to relations of class those of race, ethnicity and gender. A fuller account of these issues would, I believe, be assisted through a reading of Weber (e.g. Weber, 1978). 
My primary concern at this point is the concept of 'semantic variety', which is the product of speakers' ideological stances, social positions, and complex social relations. 'Semantic variety' is ideological stance made manifest in discourse. Hasan has produced the most robust analysis of a semantic variety, correlating most closely with speakers' social position (Hasan 2009c). The data from her project also permitted observations about early socialisation and the process of articulating roles based on gender, a further illustration that semantic variation is not 'simply indexical'; rather it is 'non-arbitrarily related to ideologies of gender and social class' (Hasan 2009d: 400). In defining her concept of 'semantic variation', Hasan drew on Whorf's notion of 'configurative rapport' (Whorf 1956). For Whorf, 'configurative rapport' was primarily a grammatical phenomenon, though with semantic consequences. In Hasan's concept of semantic variation, this relation is inverted. Configurative rapport becomes a semantic concept, realised, from below, in lexicogrammatical patterning, and related from above to the construal of ideology as the higher level contextual phenomenon' (Hasan 2016a: 120). Semantic variation 'does not simply signal ideology; rather, this is how language participates in creating, maintaining and changing ideological stances’ (Hasan 2016a: 120).

In developing her account of semantic variation, Hasan argues that a configurative rapport has a 'nucleus', described as a semantic feature which acts as 'the pivot' attracting 'sympathetic" elements' (Hasan 2009e: 447). At the lexicogrammatical level, 'strong lexical nodes act as a 'magnet' for specific collocates'; the node's 'inner nature' supports 'predictions about what will go with what' (Hasan 2009e: 447). The formulation recalls Firth's claim that some lexical items are 'sociologically saturated' (Firth 1957b). Hasan also characterises this process in semantic terms, arguing that 'a strong "semantic node" will attract other predictable semantic features ... semantic nodes and the clusters they attract are important for the deep understanding of a discourse because they relate directly to the construal of context' (Hasan 2009e: 447). The processes by which, over time, linguistic choices by speakers produce favoured configurations is obviously complex and difficult to track. Large scale corpora, however, can reveal consistencies in linguistic selections over large numbers of instances, and potentially over a diverse array of registers. Corpus linguistics has limitations, in that automated analysis of these big data sets restricts linguists to the study of lexical co-patterning, though with the option to explore, via manual analysis, some colligational patterns. But ideological patterning is prosodic (Hasan 2009e), that is, distributed across lexical and grammatical selections, and across metafunctions. Lukin (forthcoming) explores a case study of distinct orientations to the construal of organized violence in media discourse, which is well explained by the tenets of Hasan's model.

Text, or 'text-in-context' as Hasan began to say late in her career (Hasan, 2014) is the ecological environment in which ideologies are established, maintained, and potentially challenged. The intricacy of text is, therefore, part of ideology's invisibility. And though ideology is a form of semantic variation that cuts across text types, the individual texts through which ideologies exert their force also simultaneously manifest register variation. It is possible, then, to argue, that different forms of the text-in-context relation differ in their ideological affordances. To pursue this claim, I turn now to the analysis of one kind of text-in-context, to consider its place in the maintenance of ideological meanings which legitimate and naturalise the use of organised violence in pursuit of geopolitical ends. The specific text (see Table 1) is from a corpus of TV news reports, 
Table 1 Sample text: from ABC TV news reporting of 2003 invasion of Iraq

\begin{tabular}{|c|c|}
\hline SPEAKER & MESSAGE \\
\hline Studio Host 1 & Tonight the war against Iraq begins with Baghdad under attack \\
\hline Studio Host 2 & President Bush promises to disarm Saddam and free the Iraqi people \\
\hline George W. Bush & $\begin{array}{l}\text { "This will not be a campaign of half measures, and we will accept no outcome } \\
\text { but victory" }\end{array}$ \\
\hline Studio Host 1 & $\begin{array}{l}\text { Good evening. Welcome to a special edition of ABC news. The Second Gulf } \\
\text { War has begun. }\end{array}$ \\
\hline Studio Host 1 & $\begin{array}{l}\text { Just before dawn, Baghdad time, the air raid sirens went off as a series of } \\
\text { explosions rocked the city. }\end{array}$ \\
\hline Studio Host 2 & $\begin{array}{l}\text { This initial strike was limited. The main attack is expected within } 12 \text { to } 24 \mathrm{~h} \text {. } \\
\text { Here's [[how the day developed]]. Within } 90 \text { min of the deadline [[passing]] } \\
\text { [[for Saddam Hussein to leave Iraq]], American bombers attacked military } \\
\text { targets around Baghdad. }\end{array}$ \\
\hline Studio Host 1 & $\begin{array}{l}\text { President George W. Bush promised a broad and concerted campaign } \\
\text { [[to disarm Iraq]]. Prime Minister John Howard said Australian FA-18 } \\
\text { Hornets were already operating over Iraq. And in a televised speech } \\
\text { Saddam Hussein accused the United States of crimes against humanity. }\end{array}$ \\
\hline
\end{tabular}

from Australia's public broadcaster, the $\mathrm{ABC}$. The corpus consists of all news reports broadcast by the $A B C$ via their 7 pm evening news bulletin between 20/03/2003 to 02/ 04/2003 (a 14-day period, c. 45, 000 words). I make reference to this corpus in my discussion of the individual text. The text is the preview element of the news bulletin from 20/03/2003 announcing the beginning of the 'war against Iraq'. A fuller study of this text can be found in Lukin (forthcoming).

\section{Ideology and text-in-context: A case study}

Given the centrality of tenor to semantic variation, I will organise this discussion drawing on Hasan's more recent network for tenor, in which she proposes that tenor (or 'interactant relations' as she later called this parameter) involves three simultaneous, systems - textual Relation, agentive Relation, social Relation (Hasan, 2014). While in one sense the relation is obvious - it is that between a news provider and news consumers - it is in more deeply understanding the nature of the context that we can begin to appreciate how texts such as this do their ideological work. Hasan's tenor network, though rudimentary and undoubtedly requiring revision - as she would herself have said - allows us to engage in an act of 'defamiliarisation', that is, to take something so apparently self-evident, and explore its cultural place and its cultural affordances. The aim here is to understand what the language of a text is a product of, and what this text helps us understand about the nature of this context. More specifically in relation to the problem of ideology, we also want to consider how this text-in-context configuration provides a particular and powerful niche for particular and powerful kinds of ideological dissemination.

Hasan has emphasised the permeability of the contextual parameters, meaning that features from one contextual parameter are not only likely to foreshadow specific coselected features within that same parameter, but to correlate with particular features in other parameters. While the probabilities of a choice in one system leading to a particular choice in another is also a feature of the lexicogrammatical stratum (Nesbitt \& Plum, 1988), Hasan suggests that the phenomenon of 'default choice' might have a distinct character at the stratum of context, because although context is partly construed 
by language 'it can never be dissociated from the material and institutional aspects of a culture' (Hasan 2016b: 237). This example text, as an instance of an 'inherently displaced register' (Hasan 2015), illustrates Hasan's point. Starting from the system of TEXTUAL Relation (see Fig. 4), let us note that the addressee for this text is of the type [absent: category: imaginary]. Specifically, the addressee is some section of 'the public', and though not without some identifiable attributes, is not directly knowable. Thus, the text speaks to 'a stereotype, a socially defined category'; all attributes of the interactant relations in this text - the relative status of speaker and addressee, the social distance which obtains between them, and the specific attributes of the addressee - are wholly constructed by the text's 'interior relations' (Hasan 2016b: 266).

This fact of the context will predict not only other selections pertaining to tenor - for instance, that the social distance must be [distant] rather than [close] - but features also relevant to the other two parameters. Regarding the field systems of MATERIAL ACTION, VERBAL ACTION, and SPHERE OF ACTION, the text construes the features [deferred], [constitutive] and [specialised \& institutionalised] respectively (Hasan 2016b). Certain features of mode are also predicted on the basis of the text being displaced. With a distant, unknowable addressee, no overlap between the production point and the reception point is possible. In other words, the material situational setting (Hasan's 'MSS' (Hasan 2005c)) of production is distant from the MSS of reception. Hasan argued that under these conditions, the material contact must be [graphic], though this is not the

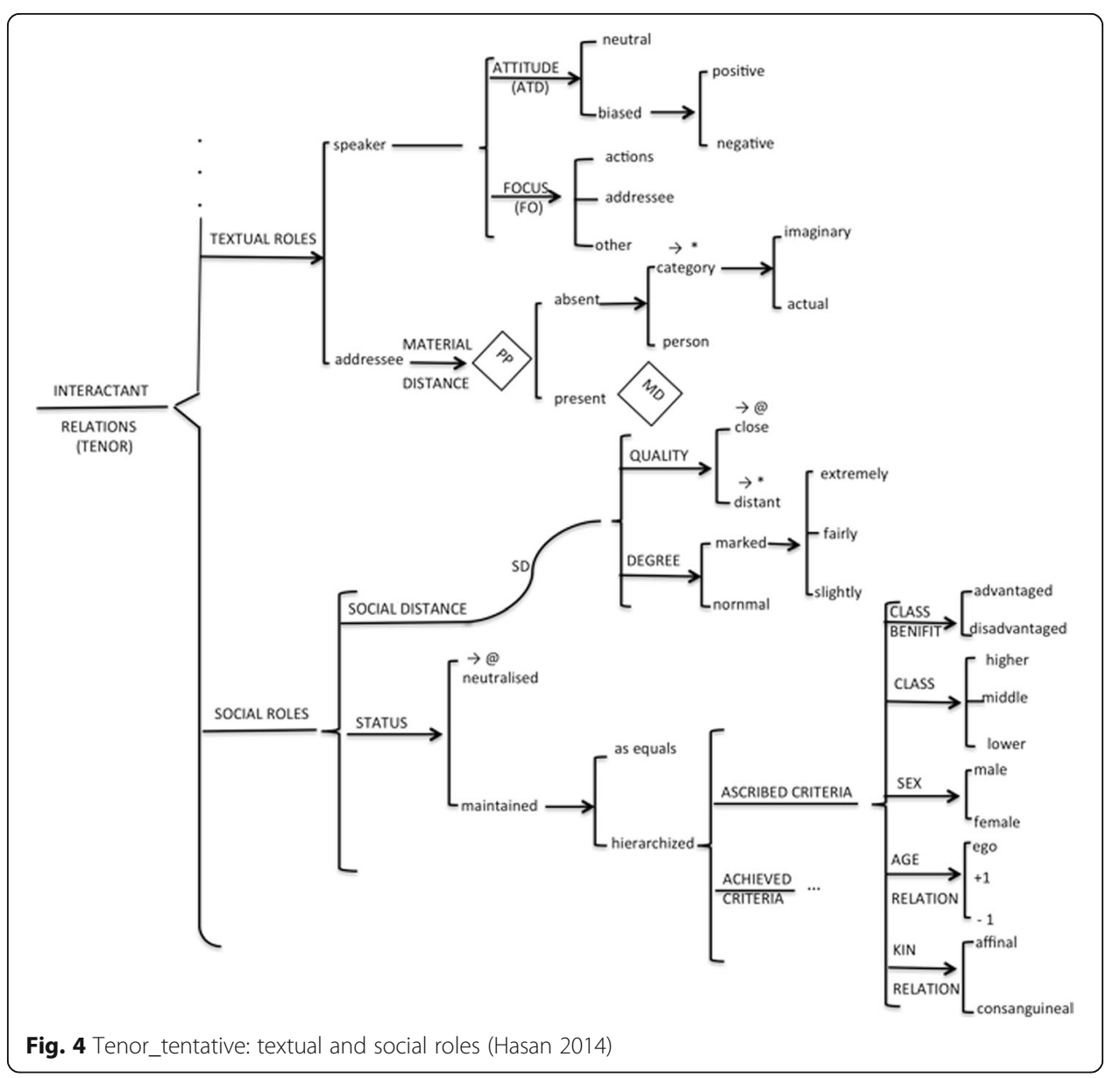


case for this register: television news is projected via a phonic channel. But in all other respects, this kind of text shares other standard mode features of displaced registers Hasan outlines (Hasan 2015).

The addressee for this particular kind of displaced register is 'the public'. While this kind of category of addressee appears self-explanatory, the 'public' of mass media is a product of historical, cultural, and technological evolution, in which the rise of news media has played a central role. News has enabled the construction of ever larger mass audiences. The emergence of news media, first as newspapers from the seventeenth century (the first edition of an English newspaper was printed in Amsterdam in 1620 (Stephens 2007)) then via radio and television in the twentieth century, and digital platforms in the late 20th and into the twenty-first century, both produced and required a 'public sphere' (Allan 1997; Habermas 1991; Malešević 2010). Technological developments have been crucial to these processes. The effect of the arrival of telegraph technology in the mid-nineteenth century on the public experience of time and space was a significant step in the construction of 'a public' (Boyd-Barrett \& Rantanen 1998). Soon after this technology was taken up by news services, the publisher of the New York Herald commented:

No better bond of union for a great confederacy of states could have been devised ... The whole nation is impressed with the same idea at the same moment. One feeling and one impulse are thus created and maintained from the centre of the language to its uttermost extremities (Stephens 2007: 216).

But the broader cultural and social change of which the development of news media is a key part needs also to be acknowledged. Thus, the kind of interactant relation we witness in this text is part of processes entailed in modernity, processes in which 'the public' is both an agent and a product. As Malešević writes:

the unprecedented structural and organisational transformation of social orders brought about by modernity have, as Nairn (1977) aptly puts it, invited ordinary people into history. In other words, the bureaucratic organisation of modern states, the spread of secular, democratic and liberal ideas, the dramatic increase in levels of literacy, the expansion of cheap and affordable publishing and the press, the extension of the military draft and the gradual development of the public sphere, among others, have all fostered the emergence of a new, much more politicised citizenry. Whereas the medieval peasantry generally had neither any interest in, nor the possibility of, politically engaging in the working of the polities they inhabited, the people of the early modern world were not only receptive to new political interpretations of their reality but were also able and willing to take an active part in these political processes (Malešević 2010: 9-10).

Given the collective nature of the addressee, does this make the system of social relation proposed by Hasan irrelevant? Do addressees which are 'imaginary' have social attributes, described by Hasan via a combination of 'ascribed' and 'achieved' criteria? (See Fig. 5, a slightly revised and elaborated network for social roles, from Hasan 2015). The individuals consuming the text produced on behalf of media 


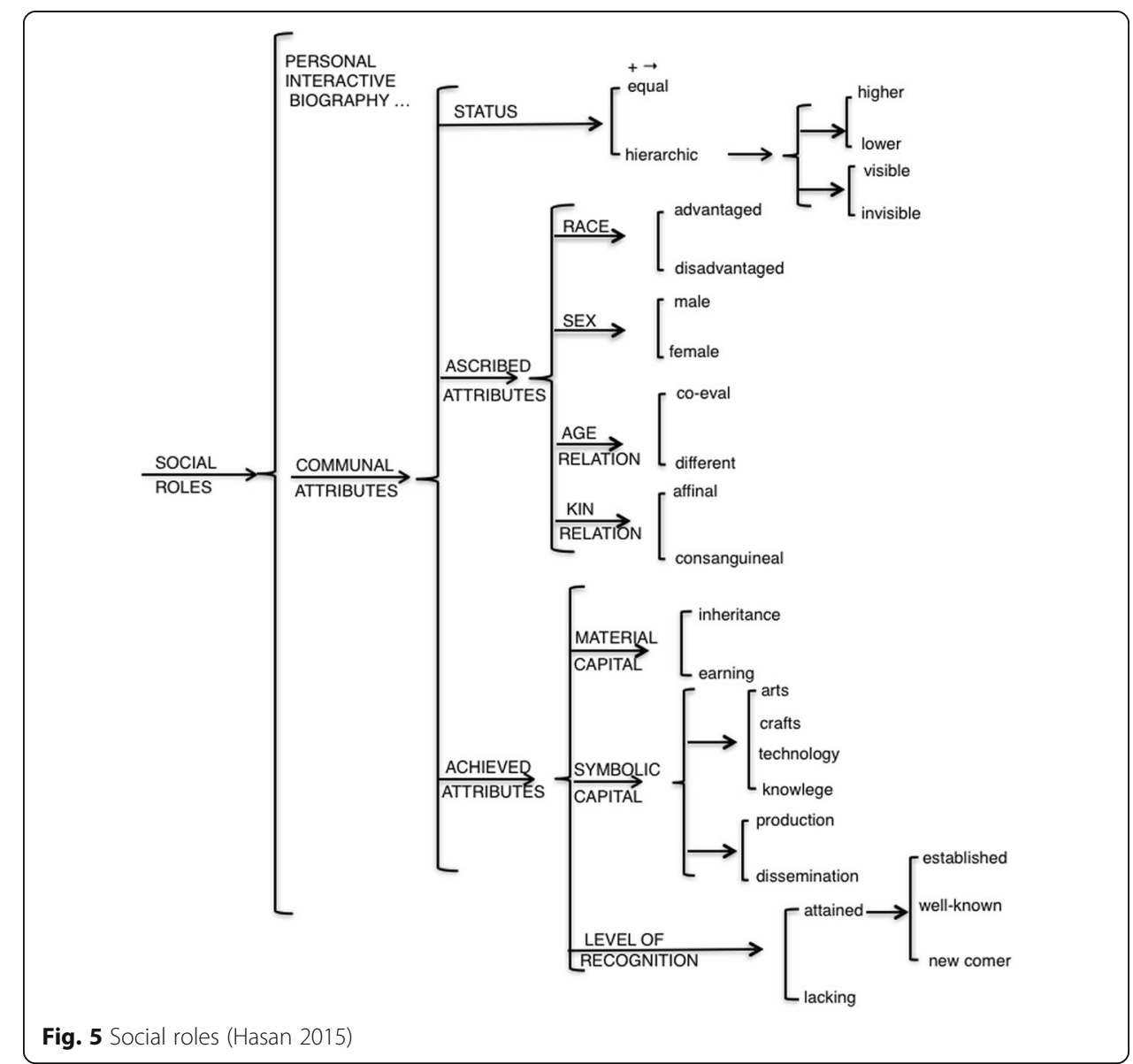

organisations most certainly do, and there is no doubt that their material capital in particular has been of interest to news purveyors, whose news products deliver an audience to business. No text speaks to the whole world, not even those produced by news services with global audiences. This particular text is for an Australian audience, and despite its putative neutrality (see below), clearly shapes the experience of these events for its audience. In so doing, it works with established, and largely unconscious, orientations to the subject matter of the news broadcast. The text is speaking to a certain kind of cultural formation, to addressees with a shared symbolic capital, through which ideologies of shared nationalism are at work. Lukin (2014a) discusses the projection by the $\mathrm{ABC}$ of a nationalistic fervour in its reporting of this event.

What kind of speaker produces this kind of text? I noted earlier that the context involves a distance between the MSS of production and that of reception. As a consequence, some kind of transmission technology is implied, and this contextual feature produces the potential - actualised in this example - for a division of labour between production and transmission. The 'speaker' in this context is, therefore, a distributed role - distributed across both the 'material' and the 'semantic' channels (Hasan 2015 uses this terms in place of 'channel' and 'medium' respectively). Part of the specialised role of news readers is the capacity to adopt a certain kind of phonological patterning, 
one that heightens the newsworthy feel of the text (Lukin 2014b; van Leeuwen 1992). The material channel has a register-specific, ritualised, quality. But this work does not exhaust the role of speaker. The texts which these news readers turn into sound waves are produced through a complex division of labour (from around the 1850s onwards, news texts begin to be produced not by sole individuals but by hierarchical teams (Stephens 2007)) embedded in hierarchical, corporate structures. News has long been a business. Some of the very first transnational corporations were in the business of selling news (Boyd-Barrett \& Rantanen 1998). Sociologists Boyd-Barrett and Rantanen describe news as 'a process that lies at the heart of modern capitalism,' and a commodity 'gathered and distributed for the three purposes of political communication, trade and pleasure'. News, thanks in particular to the rise of transnational news agencies, such as Havas, AP, and Reuters, contributed to processes such as 'the construction of national identity' and 'to imperialism and the control of colonies' (Boyd-Barrett \& Rantanen 1998: 1-2). News corporations function as agencies within what Bernstein refers to as 'the field of symbolic control'; such agencies regulate 'the means, contexts and legitimate possibilities of cultural reproduction' (Bernstein 1990: 46). News is a commodity - a symbolic commodity - subject to market transactions.

Thus, the 'news reader' speaks this text, but does not voice it as the unique individual he or she undoubtedly is. Rather, the 'speaker' of a news text speaks a corporate, homogenizing speech. The texts of this corporate voice are created, in the first instance, by journalists, as part of a news production hierarchy. Journalists are professionals trained and qualified through university study (the University of Missouri was the first to establish a specific school of Journalism, in 1908 see (Stephens 2007)). Textbooks for students of journalism, offering to make visible the various skills required in modern journalism, abound. For example, Boyd's Broadcast Journalism: Techniques of Radio and Television News, which ran to five editions, includes sections on the nature of news and news gathering, writing for broadcast media, conducting interviews, presenting news, editing, scriptwriting, still photography and videojournalism (Boyd 2001). Journalists are subject to training, and their texts are subject to further institutional processes of selection, shaping, and regulation. The authors of news text are habituated to particular principles of relevance in the construction of news.

The particular text selected here comes from Australia's public broadcaster, the Australian Broadcasting Corporation $(\mathrm{ABC})$. The $\mathrm{ABC}$ is run by its board, a committee whose authority comes through legislation (1983 ABC Act), which prescribes its duties. These duties include ensuring that 'the gathering and presentation by the Corporation of news and information is accurate and impartial according to the recognized standards of objective journalism' (ABC Act, 1983; emphasis added). Looking to Hasan's options for speaker in the TEXTUAL RELATION system, the speaker ATTITUDE is [neutral]: the text has no obvious lexical selections that would be considered to function as overtly evaluative (Martin \& White 2005), except in the paraphrase of the Iraqi president, already a much discredited figure. The language which construes this apparent impartiality and objectivity in news text itself has a rich history, which various scholars have attempted to sketch. Allan, for instance, describes the displacement of the mercantile and explicitly partisan press by the 'penny press' as a driving force in the establishment of standardised forms, topics and tone in news discourse: 
as an elite press previously preoccupied with partisan interests gave way to a popular one which sought to prioritise a public interest, the goals of explanation and critique were increasingly being played down in favour of a panorama of facts ostensibly devoid of evaluative comment (Allan 1997: 305).

The arrival of telegraph technology, the rise of news agencies (which specifically trained their journalists in writing news reports), the professionalisation of journalism, and the growth of science, have also all been cited as factors in the homogenesing of structure (e.g. the 'inverted pyramid' structure) and style in news reporting. These 'emergent conventions of wire service reporting, apparent as they were not only in the routinisation of news-work practices, were clearly helping to secure the codification of objectivity as a normative standard' (Allan 1997: 306). In 1923, the American Society of Newspaper Editors published its 'canons' of journalism at its first convention, which included 'impartiality'. A commitment to 'impartiality' was also part of the discourse around the establishment of a news broadcasting in the BBC in the 1920s, encoded in the BBC Charter and later in 1954 formally enacted through the 1954 Television Act. This absence of appraisal lexis is explained then not by individual choices of the individuals responsible for the construction of this individual text: they are part and parcel of its 'semo-history' (Halliday 2003e). This 'neutrality' is no doubt part of what makes the ABC 'Australia's most trusted news source' (see Essential Poll: http://www.essentialvision.com.au/trust-in-media-8).

A further dimension of the context, pertaining to field, is also relevant here. Hasan (Hasan 2009f) proposes the system PERFORMANCE OF ACTION, and suggests two primary options: [bounded] to describe a context in which a single interaction completes the social process, and [continuing] for those in which a sequence of interactions is involved. Where [continuing] is the relevant option, a further choice is opened up, that between [sequenced] and [conditional], the first referring simply to a series of interactions that unfold in time, the second to denote a sequence in which some particular interactions must occur for later ones to take place. News texts vary with regards to this option: some reports are [bounded]: they require a single text for their details to be reported. But the reporting of action of this event, with its prospective consequences, gives it the status of a [continuing: sequenced] event, one which involves numerous news reports, both before and after this particular instance. That this is an ongoing event under the gaze of the international media has a further implication: it makes it an event which can be subject to media management. This feature of the context as [continuing] is related to the nature of the focus of the state: a report on inter-state warfare. The people, things and objects subject to refraction through this news report are tied to nation states, and tied up with the most powerful men and agencies in our world. Protagonists in these events with vested interests can, and certainly did, expend resources to intervene in how these unfolding events would be construed in the press. Rampton \& Stauber (2003) provides some details of the mechanisms by which interested parties, including the US and UK governments, sort to invisibly direct media coverage of this event. Barstow (2008) tracks some of the interpenetrations between media, the government and the 'defense' industry: ex-military officials contracted to either or both the US government and arms manufacturers, presenting as independent military 'experts', projected the views of their government and of the military corporations they were paid 
by. Lukin (2012) explores the use of 'military experts' in ABC current affairs coverage of the 2003 invasion of Iraq.

This putative neutral stance of the speaker, constructed through unconscious, habituated patterns of language use, provides a mechanism whereby the wording of this news report will follow the dominant narrative. As Halliday has argued, language is probabilistic: part of the meaning of lexicogrammatical selections is in their relative frequencies. The veneer of impartiality involves the selection of dominant - the most probable - lexical choices. This constraint on linguistic choices in this text-in-context relation carries particular significance when the reporting entails a domain of human action which is on a large scale (it involves action by human collectives, governed by international law), is destructive (it involves the wielding of humanity's most lethal inventions), and impinges on one of the world's most lucrative industries (the global arms trade, see e.g. Feinstein, 2011).

This complex of contextual factors explains how a text is a vehicle for a certain semantic variety, an ideological orientation towards the events being reported. One text is no evidence for a particular variety - but I describe elsewhere (Lukin, 2008; Lukin, 2013; Lukin forthcoming) the powerful effect of choosing 'war' as the unifying abstraction to explain the phenomena being reported. 'War' is an instance of a strong lexical node (Hasan 2009e), which attracts other predictable semantic features (Lukin forthcoming). Once the violence perpetrated by the US and its allies is considered an instance of the category 'war', it is difficult to hear a counter-voice offering an alternative construal. I say this despite the fact that the text gives space to Saddam Hussein's charge that the US was committing crimes against humanity through this invasion: Lukin (2014a) shows that Iraqi perspectives were given a very minimal place in the $\mathrm{ABC}$ coverage of this invasion, and that it was overwhelmingly dominated by official Coalition spokespeople.

The designation 'war' validates the use of force for the contest of power. The linguistic system is ever expanding: it offers speakers the means to construe the Coalition invasion as, for instance, 'aggression' or 'violence'. In this text such designations are not taken up. Across a larger corpus of ABC TV news reports, from which this text is chosen, the pattern in this text holds across a larger sample of news discourse pertaining to the 2003 Iraqi invasion (Lukin forthcoming). In the ABC corpus, there is a single instance in which the $\mathrm{ABC}$ allows the voice of Iraq's Foreign Minister to call the actions of the 'Coalition' 'colonial aggression'. It never uses this term itself. In addition, the $\mathrm{ABC}$ associates 'violence' predominantly with anti-war protests, but never with the actions of the 'Coalition' (Lukin, 2013). The ABC avoids any association between 'war' and 'violence'. In avoiding what might be considered a rational association, the $\mathrm{ABC}$ confirms a deep paradigm: drawing on the 100 million word, multi-generic, British National Corpus, the probability that a text with the word 'war' will also include the word 'violence' is $1 \%$ (Lukin forthcoming).

These two words - 'war' and 'violence' - have entirely distinct collocates, linguistic infrastructure, and thesaurus locations, which enables them to function as strong lexical nodes in the construal of events to which they can be reasonably applied (Lukin forthcoming). The concept of 'war' is associated with the rational, purposeful, organised, and official use of force. It predicts a largely intransitive construal of the violence - in the text the 'war on Iraq' 'begins', as if by itself; Australia's FA-18 Hornets are simply 'operating over Iraq'. The 'war' is given a proper name (the Second Gulf War). Human 
agency in its prosecution is obscured or mediated, via human collectives, abstract things and processes, by giving agency to technology (e.g. 'American bombers attacked military targets'). My analysis of another text from this corpus shows that textural relations allow the belligerents enacting the violence which defines this event as 'war' to be dissociated, in one and the same text, from the acts of violence they are perpetrating (Lukin 2014b). 'War' is accompanied by a focus on 'operations' and 'the campaign'; the actions of the agents of the belligerents will be construed as 'just doing their job' and 'getting down to work'. The language will have bureaucratised overtones, since 'war' is the expression of the 'cumulative bureaucratisation of coercion' (Malešević 2010).

A text construed and transmitted to a large, passive and largely trusting audience by a corporate voice, subject to government oversight and pressure, governments who are increasingly connected to the 'military industrial complex', is the perfect design for the dissemination of a message that validates the pursuit of geopolitics via organised violence. This harmony between the register of news and ideologies pertaining to organised violence explains the long interest it has held for linguists and discourse analysts. Of course, this register does not do it on its own. 'War,' whose history is associated with the rise of human civilisation (Eckhardt 1992), is saturated with history and mythology, and this semo-history acts on each and every text in which 'war' is invoked. Billig has observed the power of 'banal nationalism' (Billig 1995), and Bourke argues that our ways of life are now so deeply militarised that we cannot see a distinction between 'civilian' and 'military' (Bourke 2015). Such descriptions of the cultural context help us understand and articulate the absent, imaginary addressee that this text both shapes and is shaped by.

\section{Conclusion}

While this text demonstrates the projection of a corporate voice, not all journalism can be characterised in this fashion. As already noted, the same register is open to variant ideological positions - in Lukin (forthcoming) I explore a text which provides a strong contrast to the one considered here. This leads to a further query about the relations of register and ideology: is it possible that some registers are more open to ideological variation than others? Halliday makes a distinction between texts which are 'largely transparent', where there is a 'fairly direct link' between the contextual configuration (Hasan 1985) and the grammar of the texts which 'present a more or less discordant mix of multiple voices' because their 'context embodies internal contradictions and conflicts' (Halliday 2007: 117118). Halliday argues that some registers are open to more ideological contestation than other registers because of the features of their context of situation, a claim which invites linguists to explore the relationship of particular registers to particular ideologies. And while all linguistic theories are ideological, this does not have to mean that they are all equal in their ability to make the work of ideology visible.

\section{Endnotes}

${ }^{1}$ See Hasan 2009 for a critique of the lack of sociological connection in mainstream sociolinguistics.

This paper was first presented as a plenary paper at the First Halliday and Hasan International Forum on Language, held at Guangdong University of Foreign Studies, under the auspices of the Halliday and Hasan Fund for the Study of Language and Other Systems of Meaning. 
Authors' contributions

Not applicable.

Ethics approval and consent to participate

Not applicable.

\section{Competing interests}

The author declares that he/she has no competing interests.

\section{Publisher's Note}

Springer Nature remains neutral with regard to jurisdictional claims in published maps and institutional affiliations.

Received: 3 August 2017 Accepted: 6 November 2017

Published online: 16 November 2017

\section{References}

Allan, Stuart. 1997. News and the public sphere. In A journalism reader, ed. Michael Bromley and Tom O'Malley, 296329. London and New York: Routledge.

Barstow, David. 2008. One Man's military-industrial-media complex. The New York Times. November 28: 2008.

Bernstein, Basil. 1987. Social class, codes and communication. In Sociolinguistics/-Soziolinguistik: An international handbook of the science of society, ed. Herausgegeben von Ulrich Ammon, Norbert Dittmar, Klaus J. Mattheier, and Peter Trudgill, 563-579. Berlin: Walter de Gruyter.

Bernstein, Basil. 1990. Code, modalities, and the process of cultural reproduction: A model. In Class, codes and control Vol IV: The structuring of pedagogic discourse, 13-62. London: Routledge.

Billig, Michael. 1995. Banal nationalism. London: Sage.

Bourke, Joanna. 2015. Deep violence: Military violence, war play, and the social life of weapons. Berkeley, CA: Counterpoint. Boyd, Andrew. 2001. Broadcast journalism: Techniques of radio and television news. Oxford: Focal Press.

Boyd-Barrett, Oliver, and Terhi Rantanen. 1998. The globalization of news. In The globalization of news, ed. Oliver BoydBarrett and Terhi Rantanen, 1-14. London: Sage.

Eagleton, Terry. 1991. Ideology: An introduction. London and New York: Verso.

Eckhardt, William. 1992. Civilizations, empires, and wars: A quantitative history of war. Jefferson, North Carolina: McFarland \& Company Incorporated.

Fairclough, Norman. 1992. Discourse and social change. Cambridge: Blackwell.

Fairclough, Norman. 2010a. General introduction. In Critical Discourse Analysis: The critical study of language. Second Edition, 1-21. Harlow, England: Longman.

Fairclough, Norman. 2010b. Language and ideology. In Critical Discourse Analysis: The critical study of language. Second Edition, 56-68. Harlow, England: Longman.

Feinstein, Andrew. 2011. The shadow world: Inside the global arms trade. New York: Picador.

Firth, John R. 1957a. A synopsis of linguistic theory, 1930-1955. In Studies in linguistic analysis, 1-32. Special Volume of the Philological Society. Oxford: Basil Blackwell.

Firth, John R. 1957b. Modes of meaning. In Papers in linguistics 1934-195, 190-215. London: Oxford University Press.

Foucault, Michel. 1972. The archaeology of knowledge. London: Tavistock.

Habermas, Jurgen. 1991. The structural transformation of the public sphere: An inquiry into a category of Bourgeous society. Cambridge MASS: MIT Press.

Halliday, M. A. K. (1999) The notion of 'context' in language education. In Ghadessy (ed.) 1st published in T. Lê and M. McCausland (eds) Language Education: interaction and development 1-26. Launceston: University of Tasmania. Reprinted in J. J. Webster (ed.) Collected Works of M. A. K. Volume 9. London and New York: Continuum.

Halliday, M.A.K. 2002. How do you mean? In On grammar. Volume 1 in the collected works of M.A.K. Halliday, ed. Jonathan Webster, 352-368. London: Continuum.

Halliday, M.A.K. 2003a. Language and the order of nature. In On language and linguistics. Volume 3 in the collected works of M.A.K. Halliday, ed. Jonathan Webster, 116-138. London and New York: Continuum.

Halliday, M.A.K. 2003b. On language in relation to the evolution of human consciousness. In On language and linguistics. Volume 3 in the collected works of M.A.K. Halliday, ed. Jonathan Webster, 390-432. London and New York: Continuum.

Halliday, M.A.K. 2003c. A recent view of missteps in linguistic theory (Review article of John M. Ellis, Language, Thought and Logic) In On Language and Linguistics. Volume 3 in the Collected Works of M.A.K. Halliday, ed. Jonathan Webster, 232-247. London and New York: Continuum.

Halliday, M.A.K. 2003d. On the architecture of human language. In On language and linguistics. Volume 3 in the collected works of M.A.K. Halliday, ed. Jonathan Webster, 1-29. London and New York: Continuum.

Halliday, M.A.K. 2003e. The history of a sentence. In On language and linguistics. Volume 3 in the collected works of M.A.K. Halliday, ed. Jonathan Webster, 355-374. London and New York: Continuum.

Halliday, M.A.K. 2007. Literacy and linguistics: A functional perspective. In Language and education. Volume 9 in the collected works of M.A.K. Halliday, ed. Jonathan Webster, 97-129. London and New York: Continuum.

Hasan, Ruqaiya. 1985. The identity of a text. In M.A.K. Halliday and Ruqaiya Hasan, Language, Context and Text: Aspects of language in a social-semiotic perspective. Geelong, VIC/ Oxford: Deakin University Press/Oxford University Press.

Hasan, Ruqaiya. 2005a. Code, register and dialect. In Language, society and consciousness. Volume 1 of the collected works of Ruqaiya Hasan, ed. Jonathan Webster, 160-193. London and Oakville: Equinox.

Hasan, Ruqaiya. 2005b. Language, society and consciousness: Volume 1 in the collected works of Rugaiya Hasan. London: Equinox. 
Hasan, Ruqaiya. 2005c. The ontogenesis of ideology: An interpretation of mother child talk. In Language society and consciousness. Volume 1 in the collected works of Ruqaiya Hasan, ed. Jonathan Webster, 256-274. London and Oakville: Equinox.

Hasan, Ruqaiya. 2009a. Wanted: An integrated theory for sociolinguistics. In Semantic variation: Meaning in society and sociolinguistics. Volume 2 in the collected works of Ruqaiya Hasan, ed. Jonathan Webster, 5-40. London: Equinox.

Hasan, Ruqaiya. 2009b. On semantic variation. In Semantic variation: Meaning in society and sociolinguistics. Volume 2 in the collected works of Ruqaiya Hasan, ed. Jonathan Webster, 41-118. London: Equinox.

Hasan, Ruqaiya. 2009c. Semantic variation: Meaning in society and sociolinguistics. In Volume 2 in the collected works of Ruqaiya Hasan. London: Equinox.

Hasan, Ruqaiya. 2009d. Social factors in semantic variation. In Semantic variation: Meaning in society and sociolinguistics. Volume 2 in the collected works of Rugaiya Hasan, ed. Jonathan Webster, 380-402. London: Equinox.

Hasan, Ruqaiya. 2009e. The world in words: Semiotic mediation, tenor and ideology. In Semantic variation: Meaning in society and sociolinguistics. Volume 2 in the collected works of Rugaiya Hasan, ed. Jonathan Webster, 433-454. London: Equinox.

Hasan, Ruqaiya. 2009f. The place of context in a systemic functional model. In Continuum companion to systemic functional linguistics, ed. M.A.K. Halliday and Jonathan Webster, 166-189. London and New York: Continuum.

Hasan, Ruqaiya. 2014. Towards a paradigmatic description of context: Systems, metafunctions, and semantics. Journal of Functional Linguistics 1 (9). https://doi.org/10.1186/s40554-014-0009-y.

Hasan, Ruqaiya. 2015. Tenor: Rethinking Interactant relations. Unpublished manuscript.

Hasan, Ruqaiya. 2016a. Speaking with reference to context. In Context in the system and process of language. Volume 4 in the collected works of Ruqaiya Hasan, ed. Jonathan Webster, 247-354. London: Equinox.

Hasan, Ruqaiya. 2016b. Wherefore context?: The ontogenesis of meaning exchange. In Context in the system and process of language. Volume 4 in the collected works of Ruqaiya Hasan, ed. Jonathan Webster, 95-126. London: Equinox.

Lukin, Annabelle. 2008. The explanatory power of the SFL dimensions for the study of news discourse. In Proceedings from ISFC 35: Voices Around the World, eds. Canzhong Wu, Christian M.I.M. Matthiessen, and Maria Herke, 106-111. Sydney, NSW: ISFC $35^{\text {th }}$ Organising Committee.

Lukin, Annabelle. 2012. Meanings in questions: A case study of the ABC's current affairs coverage of the 2003 invasion of Iraq. Special issue. Journal of Applied Linguistics and Professional Practice 9 (1): 127-147. https://doi.org/10.1558/ japl.v9i1.127.

Lukin, Annabelle. 2013. The meanings of war: from lexis to culture. Journal of Language and Politics 12 (3): 424-444. https://doi.org/10.1075/jp.12.3.06luk.

Lukin, Annabelle. 2014a. 'Marching to Iraq with Howard': The 2003 Iraq invasion on ABC-TV. Australian Journalism Review 36 (1): 29-44.

Lukin, Annabelle. 2014b. Creating a parallel universe: Mode and the textual function in the study of one news story. In Recent studies in systemic phonology, ed. Wendy Bowcher and Brad Smith, 53-90. London: Equinox.

Lukin, Annabelle. Forthcoming. War and its ideologies: A social-semiotic theory and description. Berlin: Springer.

Malešević, Siniša. 2002. Rehabilitating ideology after poststructuralism. In Ideology after poststructuralism, ed. Siniša Malešević and lain MacKenzie, 87-110. London: Pluto Press.

Malešević, Siniša. 2010. The sociology of war and violence. Cambridge: Cambridge University Press.

Mannheim, Karl. 1936. Ideology and utopia: An introduction to the sociology of knowledge. New York and London: Harcourt, Brace \& Co., Inc.

Martin, James R., and Peter R.R. White. 2005. The language of evaluation: Appraisal in English. London and New York: Palgrave.

Nairn, Tom. 1977. The Break-up of Britain. London: New Left Books.

Nesbitt, Chris, and Guenter Plum. 1988. Probabilities in a systemic-functional grammar: The clause complex in English. In New developments in systemic linguistics, ed. Robin P. Fawcett and David Young, 6-39. London: Pinter.

Rampton, Sheldon, and John Stauber. 2003. Weapons of mass deception: The uses of propaganda in Bush's war on Iraa. Sydney: Hodder.

Reddy, Michael. 1979. The conduit metaphor: A case of frame conflict in our language about language. In Metaphor and thought, ed. Andrew Ortony, 284-310. Cambridge: Cambridge University Press.

Stephens, Mitchell. 2007. A history of news. Third Edition. New York: Oxford University Press.

van Leeuwen, Theo. 1992. Rhythm and social context. In Studies in systemic phonology, ed. Paul Tench, 231-262. London: Frances Pinter.

Vološinov, Valentin. 1973. Marxism and the philosophy of language. New York: Seminar Press.

Weber, Max. 1978. Economy and society. Berkeley: University of California Press.

Whorf, Benjamin Lee. 1956. Language, thought, and reality: Selected writings. Cambridge, MA: MIT Press.

Wodak, Ruth. 2001. What is CDA about - a summary of its history, important concepts and its developments. In Methods of critical discourse, ed. Ruth Wodak and Michael Meyer, 1-13. London: Sage. 